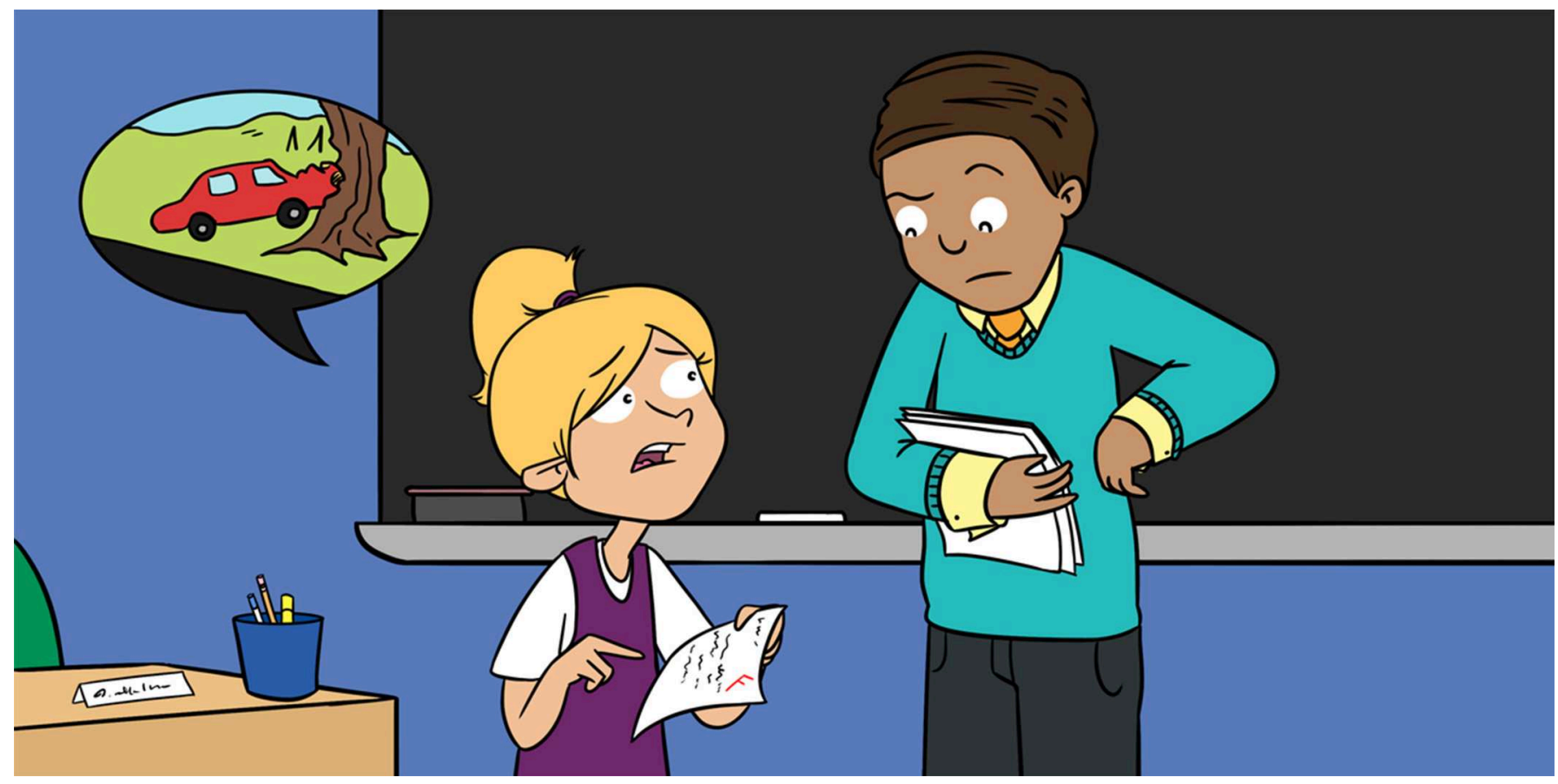

\title{
HITTING YOUR HEAD CAN RESULT IN INVISIBLE DISABILITY THAT AFFECTS YOUR BODY AND BEYOND!
}

\author{
Janet Le ${ }^{1}$, Sara Emily Morgan ${ }^{1}$, Andrew W. Porter ${ }^{1}$ and Nicole Osier ${ }^{1,2^{*}}$ \\ ${ }^{1}$ Department of Neurology, Dell Medical School, The University of Texas at Austin, Austin, TX, United States \\ ${ }^{2}$ School of Nursing, The University of Texas at Austin, Austin, TX, United States
}

YOUNG REVIEWERS:

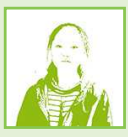

BIHAN

AGE: 14

DIBA

AGE: 13
Traumatic brain injury (TBI) can occur when someone hits his, her, or their head or experiences another type of trauma to the brain. $\mathrm{TBI}$ can have lasting effects on the body, emotions, and more! TBI is common, yet people often do not understand how serious it can be. A good understanding of TBI and its effects is important so that doctors and nurse practitioners can diagnose and treat TBI correctly. People who suffer these injuries may experience mood swings, trouble focusing, or other changes from the way they used to be. Since it may not be easy to tell at first that these problems are related to $\mathrm{TBI}$, we often refer to the long-term consequences of TBI as invisible disabilities. In this article, we will talk about the causes of TBI, the invisible disabilities people experience after a TBI, and how healthcare providers are trying to promote recovery. 
Figure 1

Living with an invisible disability after a TBI can affect a person's everyday activities. TBIs can cause physical, emotional, and learning-related changes. It is important for TBI survivors to seek out support for their invisible disabilities.
TRAUMATIC BRAIN INJURY

Brain damage as a result of a violent hit or jolt to the head.

\section{INVISIBLE}

\section{DISABILITY}

A physical, mental, or neurological condition that is not visible to others. Examples are traumatic brain injury, depression, and anxiety.
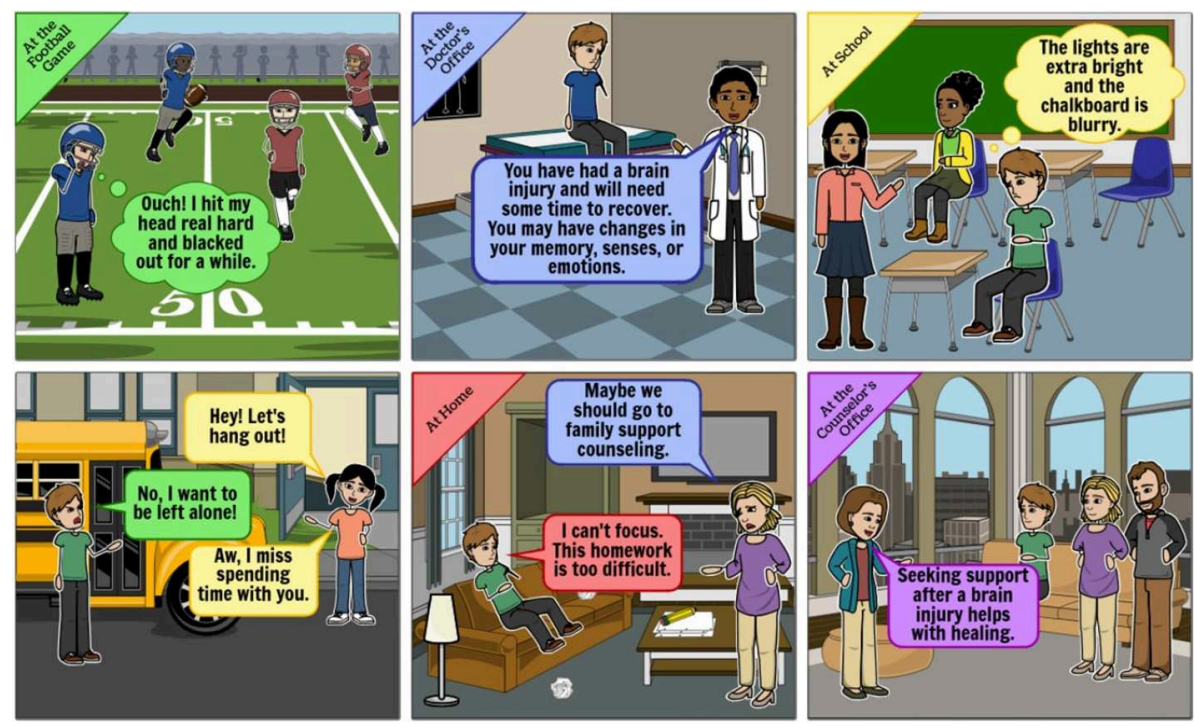

Figure 1

\section{TB| AND INVISIBLE DISABILITIES}

Traumatic brain injury (TBI) is most commonly caused by a hit to the head due to being tackled while playing sports, being involved in a car accident, or getting hit with a hard object. TBls can range from mild to severe, with some people quickly returning to school sports and others suffering permanent brain damage. The consequences of TBIs are considered an invisible disability, because they can occur in daily life, but the person does not outwardly appear to have a problem, since there is no need for a wheelchair, walker, or crutches. For example, someone who is recovering from a TBI may be dealing with subtle changes in mood, vision, and sensations in the legs.

Since many $\mathrm{TBI}$ symptoms are not obvious, this can cause others to underestimate how severe TBI can be. People may think that someone who is blaming bad grades on an injury that occurred months ago is exaggerating. Another misconception is that people can recover from TBls more quickly if they work harder in school or at physical therapy. This is not true, and if the TBI symptoms are serious enough, participating in therapy may be challenging [1]. Invisible disabilities are diverse, as shown in Figure 1, and can result in a variety of physical, emotional, and learning or memory-related challenges that are just as important, if not even more so, than any visible disability from a TBI.

Fortunately, research advances have led to a better understanding of the various TBI symptoms. There are several research methods that scientists use to study TBI. For example, some scientists ask patients to describe their experiences in their own words, via interview. Other researchers use surveys or laboratory tests. Data can be collected at a single time point, or at multiple timepoints after injury. In many studies, 
SECONDARY

\section{INJURY}

Indirect injury resulting from processes initiated by the primary injury.

\section{OXIDATIVE STRESS}

Secondary brain injury; caused by too many of some molecules and too few of others.

\section{EXCITOTOXICITY}

Secondary injury in which brain and nerve cells become too excited, preventing them from functioning properly.

\section{HYPOXIA}

Secondary brain injury in which the brain does not receive enough oxygen. including the one we will describe, patients are studied for long periods of time after they are hurt, so that researchers can see what will happen to them over the course of recovery. Additionally, experiments are often run on patient samples (like blood and saliva) to measure levels of certain proteins. The amounts of different proteins in a sample can determine how serious or mild the TBI is and these levels may be useful for tracking recovery as time goes on. With the knowledge gained from these studies, researchers hope to better educate the public about TBIs and work toward improving current treatments.

\section{PRIMARY AND SECONDARY INJURIES}

TBls have two phases. The initial injury to the head is called the primary injury and could be a bruise on the brain or a fracture to the skull. The severity of the primary injury can determine how long it will take the person to recover and whether or not a full recovery is likely [1]. After the primary injury, the brain often suffers secondary injuries, such as oxidative stress, inflammation, excitotoxicity, and hypoxia [2]. Oxidative stress occurs when certain molecules in the brain get out of balance, and this can cause permanent damage to the neurons, which are the cells that send information about the outside world to the brain [2]. Inflammation is swelling in the brain, often due to high levels of certain proteins, and it can result in even more tissue damage than the primary injury [3]. In excitotoxicity, brain and nerve cells become overly excited. Because cells need to rest just like we do, excitotoxicity can prevent cells from functioning at their best [2]. Lastly, hypoxia is when very little oxygen flows into the brain, which is a problem because oxygen is needed to feed the brain and keep it working properly. The main reason we care about these secondary injuries is that they likely contribute to long-term invisible disabilities. Since these secondary injuries often last for a while after the primary injury, treatment of the secondary injuries might be necessary. For example, if a person's brain has too much inflammation, perhaps anti-inflammatory drugs like aspirin would be useful.

\section{LONG-TERM EFFECTS OF TBI}

Every $\mathrm{TB}$ is different, leading to a wide variation in invisible disabilities. Since the brain controls everything, TBI can cause many changes in a person's movement senses, emotions, and memory. Sometimes these changes last a few months after the TBI, but other times they are permanent! The most common types of disabilities that follow TBI and their treatments are summarized in Table 1.

\section{Physical Challenges}

After TBI, physical changes involving movement and the functioning of the senses can occur. TBI survivors may have slower movements, difficulty picking up objects, weakness in the arms or legs, or 


\section{Table 1}

Possible disabilities caused by a TBI treatment strategies [4].

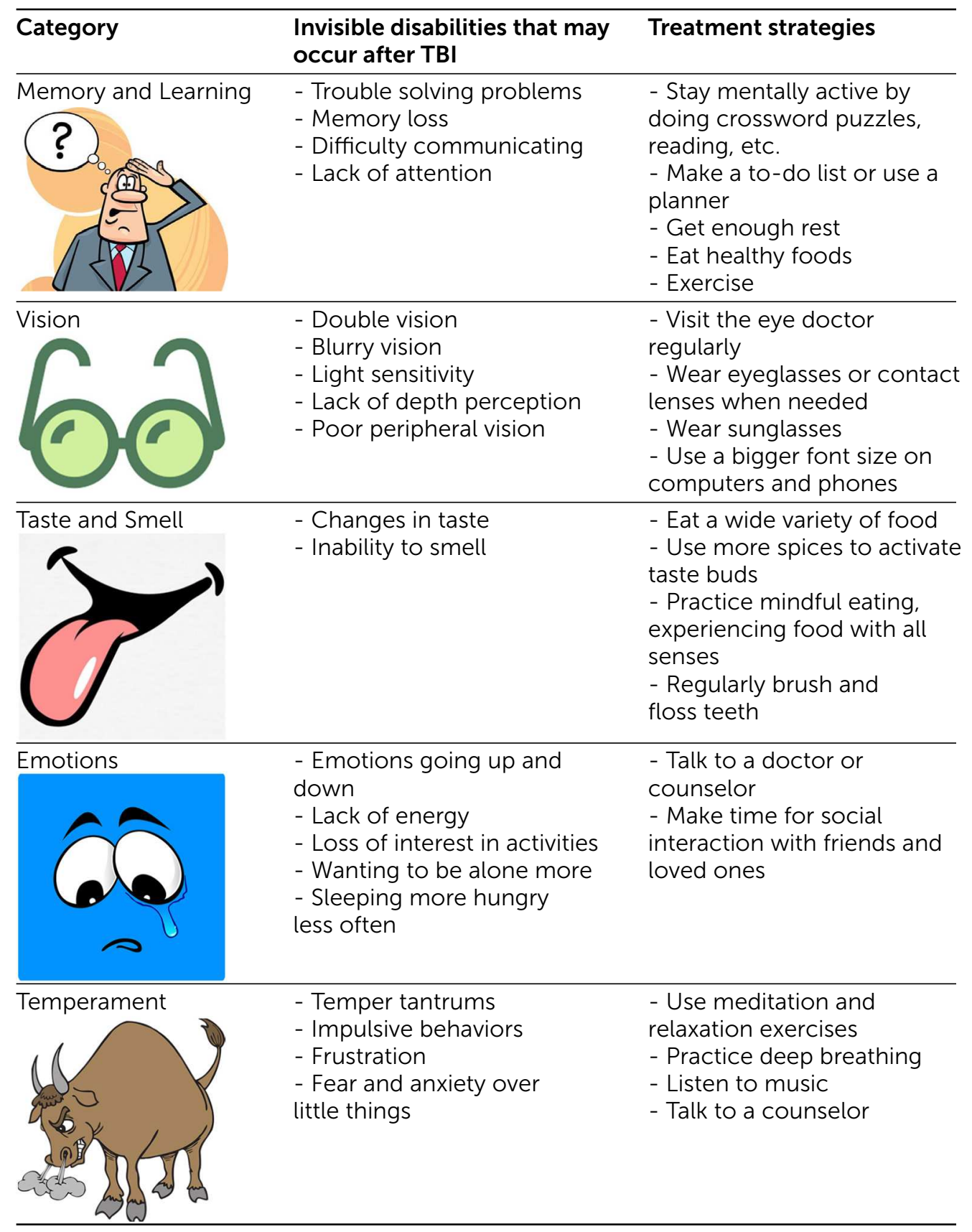

clumsiness and lack of coordination. While these symptoms may be visible to others if they are severe, milder problems may be an invisible disability [4]. Physical therapy and exercise can help a TBI patient to regain strength and coordination. Other physical changes that are typically not noticeable to others include changes in smell, taste, touch, hearing, or vision [4]! Sensory changes can affect everyday life. For example, a person's favorite food may taste bland. The sense of smell can be crucial; for example, if someone is having trouble smelling and he, she, or they walk away from the kitchen while cooking, it may not be possible to smell the smoke if something was burning! Vision changes, like blurry vision or seeing double, 
can also occur [4]. If this happens, glasses or contact lenses might be needed.

\section{Emotional Challenges}

Emotional changes of various types can occur after TBI. These changes can be so small that they are hardly noticeable or so obvious that the person seems totally different than before the TBI. Common emotional challenges after a TBI include lack of motivation, feeling sad more often, feeling anxious, wanting to spend time alone, feeling sleepier, being less excited about participating in favorite hobbies, and more [4]. A person's emotions help make them who they are, so these emotional changes following TBI can be difficult for both the person with the invisible disability and their loved ones. Therefore, it is important to be patient and kind with someone recovering from a TBI. They are not trying to act in a different way on purpose.

\section{Learning and Memory Challenges}

Learning ability, knowledge, memory, attention, problem solving, organization, and communication can all be impacted by TBI [4]. Trouble focusing on homework and lack of motivation to complete assignments could be a sign of an invisible disability. After a TBI, it can be harder to remember things like people's names or where objects were placed. Ways to combat these memory changes include studying with flashcards, making to-do lists, and using smartphone apps.

\section{TREATMENT PROGRAMS AND SUPPORT SERVICES}

People who experience an invisible disability after a TBI have unique needs. Current therapies for people with visible disabilities, such as muscular dystrophy or blindness, do not always help people recovering from $\mathrm{TBI}$. Data shows that people recovering from TBI prefer to focus on regaining important skills so that they can resume the lifestyle they had before the injury [5]. The top needs expressed by TBI survivors are improving memory, enhancing problem solving, receiving education, developing job skills, and managing emotions [5]. TBI survivors often do not get help with taking care of themselves and loved ones, or with earning and managing money [5]. Other important needs of $\mathrm{TBI}$ survivors include restoring memory and emotional control [5]. As shown in Figure 2 below, certain things are important for the recovery from TBI, including spending time with loved ones, doing things that are enjoyable and bring happiness, talking to a doctor about what is going on, and attending support groups for people who are living with invisible disabilities. It is just as important to address any invisible disabilities as it is to address visible disabilities because sensory, emotional, and cognitive health affect daily life.

It is also important to make sure that there is support for family and friends who may be affected by changes in their loved one after a 
Figure 2

Four real-life examples of the various ways TBI survivors can receive support for invisible disabilities. Clockwise from the top left, these methods include spending quality time with family and friends being physically active, such as hiking with friends, talking to a doctor or therapist, and attending a support group for people with similar experiences.

Reproduced

from Clipart Library [6].

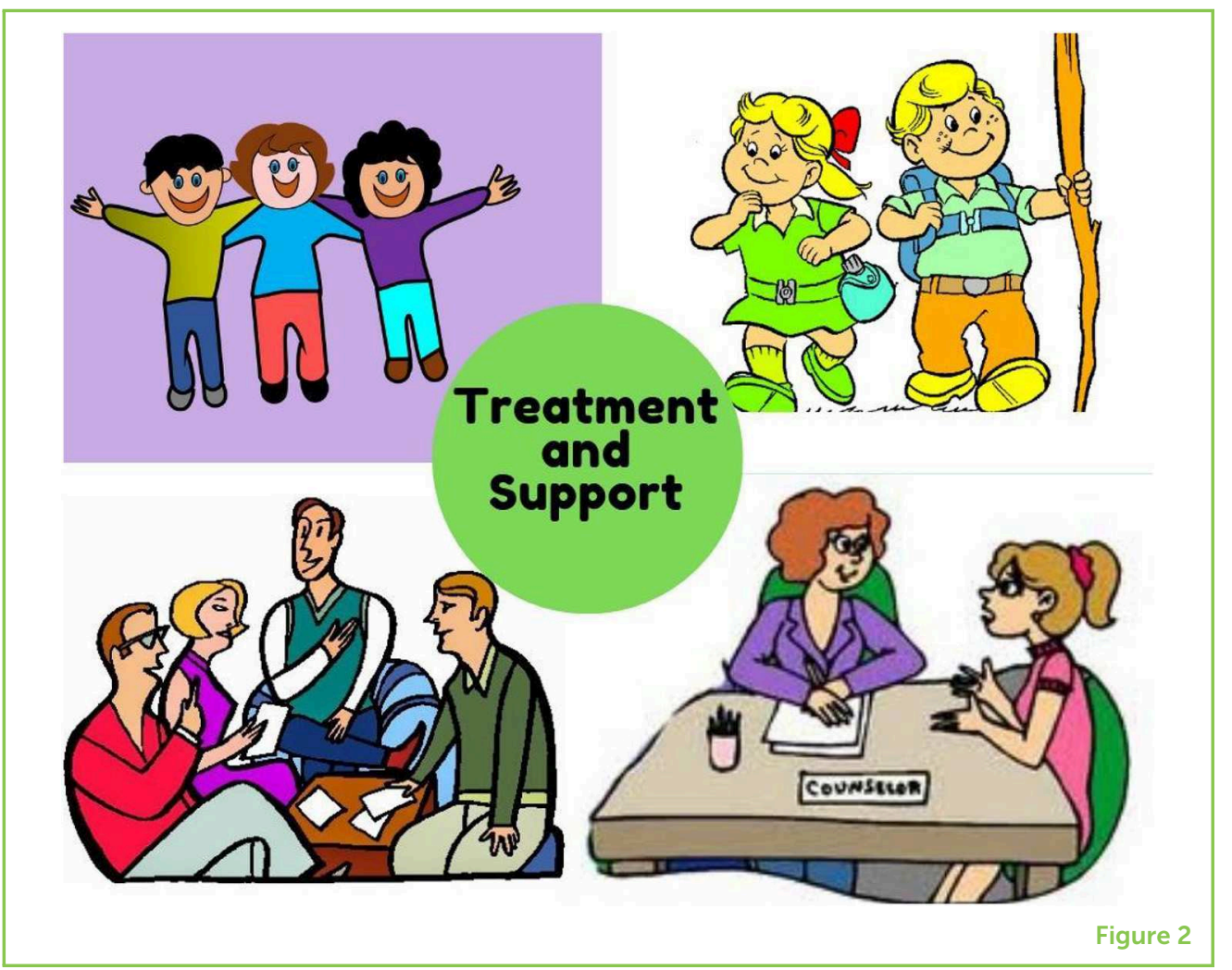

TBI, such as changes in communication, affection, and behavior [4]. Right now, the majority of help available for family and friends of TBI survivors is through hospitals, medical centers, clinics, or hotlines. Keep in mind that recovery also takes a while for the family and friends. It may be helpful for TBI survivors and the people closest to them to try to get involved in, or start, a support group for those going through similar situations. Support groups can share coping strategies and relaxation tips to use when $\mathrm{TBI}$ survivors are going through a tough time.

\section{CONCLUSION}

TBls can have many different causes and can result in a variety of effects and secondary injuries, resulting in changes in learning, memory, senses, emotions, and beyond! These secondary injuries result from brain cell or tissue damage that occurs following the primary injury. It is important to understand TBI and its possible effects on both the patient and the people they interact with. Receiving treatment when an injury first occurs, and throughout the recovery period, will help improve the outcome of a TBI [4]. Seeking support from family, friends, or health professionals is especially important when dealing with TBIs. TBIs can be scary and challenging, but with the right knowledge and tools, patients can be prepared to overcome TBI and its obstacles, both immediately and in the future. Hopefully, this article has shed light on the invisible disabilities that people face after 
$\mathrm{TBI}$, so that we can be more aware of the risks of invisible disabilities. By being more patient and understanding with ourselves or loved ones after $\mathrm{TBl}$, we can best help to promote recovery.

\section{FUNDING}

This Pl's effort was generously supported by a pilot grant from the University of Texas at Austin School of Nursing St. David's Center for Health Promotion \& Disease Prevention Research in Underserved Populations, as well as a pilot grant from The Heilbrunn Family Center for Nursing Research.

\section{REFERENCES}

1. Guilmette, T. J., and Paglia, M. F. 2004. The public's misconceptions about traumatic brain injury: a follow up survey. Arch. Clin. Neuropsychol. 19:183-9. doi: 10.1016/s0887-6177(03)00025-8

2. Bramlett, H. M., and Dietrich, W. D. 2015. Long-term consequences of traumatic brain injury: current status of potential mechanisms of injury and neurological outcomes. J. Neurotrauma 32:1834-48. doi: 10.1089/neu.2014.3352

3. Simon, D. W., Mcgeachy, M. J., Bayir, H., Clark, R. S. B., Loane, D. J., and Kochanek, P. M. 2017. The far-reaching scope of neuroinflammation after traumatic brain injury. Nat. Rev. Neurol. 13:572. doi: 10.1038/nrneurol.2017.116

4. Sander, A. M. 2002. Picking Up the Pieces After TBI: A Guide for Family Members. Houston, TX: Baylor College of Medicine.

5. Heinemann, A. W., Sokol, K., Garvin, L., and Bode, R. K. 2002. Measuring unmet needs and services among persons with traumatic brain injury. Arch. Phys. Med. Rehabil. 83:1052-9. doi: 10.1053/apmr.2002.34283

6. http://clipart-library.com/

SUBMITTED: 31 March 2019; ACCEPTED: 23 August 2019; PUBLISHED ONLINE: 04 October 2019.

EDITED BY: Danijela Serbic, Royal Holloway, University of London, United Kingdom

CITATION: Le J, Morgan SE, Porter AW and Osier N (2019) Hitting Your Head Can Result in Invisible Disability That Affects Your Body and Beyond! Front. Young Minds 7:120. doi: 10.3389/frym.2019.00120

CONFLICT OF INTEREST: The authors declare that the research was conducted in the absence of any commercial or financial relationships that could be construed as a potential conflict of interest.

COPYRIGHT $\odot 2019$ Le, Morgan, Porter and Osier. This is an open-access article distributed under the terms of the Creative Commons Attribution License (CC BY). The use, distribution or reproduction in other forums is permitted, provided the original author(s) and the copyright owner(s) are credited and that the original publication in this journal is cited, in accordance with accepted academic practice. No use, distribution or reproduction is permitted which does not comply with these terms. 

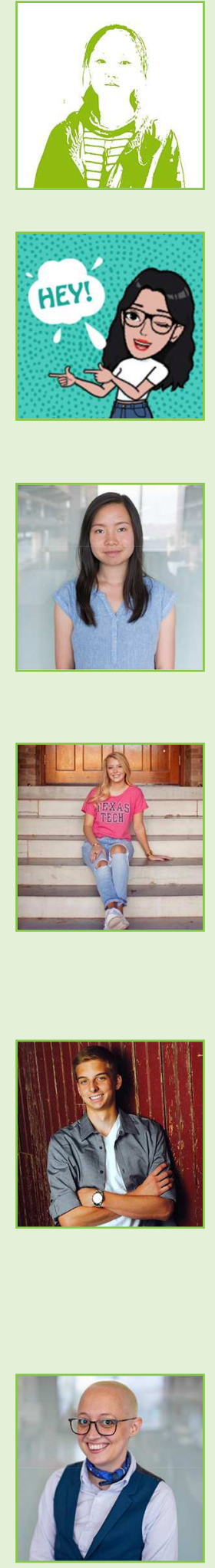

\section{YOUNG REVIEWERS}

\section{BIHAN, AGE: 14}

I am a junior school student. I started learning biology from grade one and I find it is interesting to learn about the creatures on earth. I like the extracurricular activities of biology. The secrets of the human body fascinate me a lot. I love exploring the behavior of human beings.

\section{DIBA, AGE: 13}

I do a lot of dancing and horse riding, but when I am tired I like reading books or watch documentaries. I like asking questions a lot.

\section{AUTHORS}

\section{JANET LE}

I am an undergraduate student at the University of Texas at Austin and I am pursuing a Bachelor of Science in Human Biology, as well as minors in History and Ethics and Leadership in Healthcare. After I graduate, I hope to attend medical school and become a doctor. In my spare time, I like to ski (while wearing a helmet, of course), try new restaurants, and watch movies. lejanet123@gmail.com

\section{SARA EMILY MORGAN}

I am graduate of Texas Tech University with a Bachelor of Science in Kinesiology and a Bachelor of Arts in General Studies with concentrations in Biology, Psychology, and Sociology. Currently, I am working in the medical field, with hopes of attending graduate school to become a Physician's Assistant specializing in Internal Medicine. In my free time, I enjoy spending time with my two dogs, traveling, and running. saraemmorganagmail.com

\section{ANDREW W. PORTER}

I am an undergraduate student at the University of Texas at Austin. I am currently working toward a Bachelor of Arts in Health \& Society and Economics as well as a certificate in Business Healthcare. I hope to attend medical school and become a doctor in the future. I plan to apply my business knowledge and training by entering the field of healthcare administration with the goal of improving care efficiency and quality. Some of my hobbies and interests include playing my violin, wakeboarding, and traveling. andrew.porter@utexas.edu

\section{NICOLE OSIER}

I am a principal investigator at University of Texas at Austin. I have bachelor's degrees in Nutritional Science and Nursing from Michigan State University, and a PhD from the University of Pittsburgh. My goal is to better understand what makes some individuals recover better than others after head injury. My ultimate goal is to apply new knowledge to help doctors and nurses treat people with head injury, so patients recover as well as possible. To learn more about my laboratory, visit my publicly available website: https://nicoleosier.wixsite. com/osierlaboratory/ or follow aosierlaboratory on facebook, twitter, or instagram. In my free time, I enjoy spending time with my spouse and cats and traveling the world. *nicoleosier@utexas.edu 